\title{
Política de Cotas e Meritocracia: Uma Análise da Percepção de Professores Universitários*
}

\author{
Bruna Caroline Moreira Silva ${ }^{1}$ \\ ${ }^{1}$ Mestra em Administração pela Universidade Federal de Viçosa (UFV). Viçosa, MG. Brasil. \\ E-mail: brunacarolms@gmail.com
}

\section{Wescley Silva Xavier ${ }^{2}$}

2Professor Adjunto do Departamento de Administração e Contabilidade da Universidade Federal de Viçosa (UFV). Viçosa, MG. Brasil.

E-mail: wescley@ufv.br

\section{Daniel Calbino ${ }^{3}$}

${ }^{3}$ Professor Adjunto da Universidade Federal de São João del Rei (UFSJ). São João del Rei, MG. Brasil.

E-mail:dcalbino@ufj.edu.br

Banco de dados: https:/ /doi.org/10.7910/dvn/t1u0y6

\section{INTRODUÇÃO}

Duas candidatas realizam o Vestibular da USP para o curso de medicina. Ambas chegam à segunda fase, mas apenas uma é aprovada. Uma é negra, moradora da periferia da Zona Leste de São Paulo, desde os 13 anos trabalha para ajudar a mãe. Oriunda de uma família que conviveu com a violência doméstica, estudou à noite, em escola pública. A outra é branca, mora no Morumbi, bairro elitizado da zona sul. Estudou inglês, tem alimentação saudável, cursou as melhores escolas e fez cursinho pré-vestibular. Coincidentemente, a branca quem ficou com a vaga do curso de medicina. Ambas eram concorrentes diretas, pergunta-se: quem teve mérito? (Domingues, 2005).

"Partes deste artigo foram inspiradas na Dissertação de Mestrado defendida por Bruna Caroline Moreira Silva, intitulada Desconstruindo Mitos: meritocracia e a Lei de Cotas, no Programa de Pós-Graduação em Administração da Universidade Federal de Viçosa (UFV). No artigo foram preservados trechos das entrevistas realizadas pela primeira autora, aspectos metodológicos e alguns trechos de análise; já o texto desenvolvido parte de outra abordagem teórica desenvolvida a posteriori pelos autores, cuja problematização, análise - em sua grande parte - e conclusões são originais. A pesquisa foi financiada pela Fundação de Amparo à Pesquisa do Estado de Minas Gerais (FAPEMIG).

DADOS, Rio de Janeiro, vol.65 (1): e20200166, 2022

https://doi.org/10.1590/dados.2022.65.1.258 
$\mathrm{O}$ trecho do preâmbulo representa um questionamento que perpassa as ações afirmativas a partir das experiências pioneiras nas universidades estaduais do Rio de Janeiro, Bahia, Mato Grosso do Sul e na Universidade de Brasília (UnB), no ano de 2003. No cenário acadêmico, as primeiras iniciativas de reflexão foram fomentadas por revistas especializadas e colóquios científicos entre pesquisadores da área.

No primeiro ano das políticas de cotas na Universidade de Brasília, realizou-se uma conferência com participação de 23 antropólogos que discutiram as possibilidades e limitações da ação na instituição. Em 2005, o periódico Horizontes Antropológicos fomentou um debate envolvendo 18 cientistas das áreas de antropologia, sociologia, história e genética.

Além dessas iniciativas, houve a criação de diversos comitês raciais em várias universidades federais para a análise da adesão voluntária das cotas entre os anos de 2003 e 2012. A Lei n ${ }^{\circ} 12.711$ de agosto de 2012, popularmente conhecida como Lei de Cotas, garantiu a partir de 2013 a obrigatoriedade de reserva de vagas para egressos de escolas públicas, bem como pretos $^{1}$, pardos e indígenas nas federais do país (Brasil, 2012).

A plausibilidade desse efeito foi acompanhada de discursos que remetiam a possíveis privilégios restritos a pretos e pardos, excluindo outras minorias. Dentre os discursos havia os que defendiam ser mais justo privilegiar alunos de escolas públicas, já que o problema da pouca representação de negros nas universidades estaria ligado à pobreza e à má qualidade do ensino público. Ademais, as cotas estimulariam o preconceito racial por meio da estigmatização dos estudantes beneficiados. Outro discurso recorrente remetia a uma perda de qualidade do ensino e à dificuldade de selecionar os indivíduos, uma vez que não existe identidade de cor definida no país (Menin et al., 2008).

Os argumentos apoiavam-se no valor da igualdade de oportunidades entre pretos, pardos e brancos, rejeitando, assim, qualquer medida de favorecimento a um determinado grupo. Além disso, tinham como pano de fundo os valores ligados ao esforço individual, de forma a defender que todos possuem capacidades iguais para obter sucesso, desconsiderando as desigualdades sociais históricas que atribuem privilégios. 
Não obstante, partes desses discursos foram retomadas nas disputas eleitorais de 2018 por um candidato à Presidência da República. O mesmo afirmou que as ações afirmativas seriam um equívoco, já que eram sinônimo de "coitadismo" e reforçam o preconceito. As políticas de cotas raciais, de acordo com o referido candidato, contrariam a igualdade perante a lei, pois, todos os brasileiros são uma única nação. Ademais, considera a ação não meritocrática, já que o estudo prévio de qualidade seria o caminho correto para o ingresso no ensino superior (Agência EBC Brasil, 2018).

Ainda que a fala do então candidato demonstre uma lógica simplista, observa-se que muitos dos argumentos sobre as políticas de cotas se baseiam em predições dos riscos, porém, pouco ilustrando eventos, dados ou experiências para a corroboração argumentativa (Santos et al., 2008; Velloso, 2009; Feres Jr. e Daflon, 2015), mesmo que haja dados suficientes para a análise comparativa nesses 16 anos de experiências.

Em similaridade, observa-se que a literatura nacional ainda carece de aprofundamento no que se refere ao discurso dos professores universitários, uma vez que assumem papel fundamental no processo de acolhimento ao cotista. É esse, portanto, o mote do artigo, que busca compreender: Como a ideia de justiça é manifesta a partir do discurso de professores universitários? Os argumentos reproduzem as predições dos debates iniciais ou se fundamentam em dados empíricos?

Para responder às questões centrais do trabalho, utilizaremos uma investigação empírica de natureza qualitativa na Universidade Federal de Viçosa, em Minas Gerais, apresentando os resultados de entrevistas semiestruturadas com 26 docentes efetivos da instituição.

A relevância da escolha da presente instituição enquanto recorte empírico se justifica por se tratar de uma universidade do ano de 1922 (criada pelo Decreto 6.053, de março de 1922), cuja origem remonta aos cursos na área de ciências agrárias, sob forte influência dos modelos norte-americanos de ensino. Em sua origem, a instituição estava relacionada ao poder político do mineiro e então presidente da República Artur Bernardes, que buscou atender às demandas da classe dominante agrária da Zona da Mata mineira, com a qual esteve comprometido nas campanhas eleitorais (Mendonça, 1997). 
A criação da instituição servia para reafirmar a vocação agrária de Minas Gerais na conjuntura nacional, com a tarefa de modernizar as práticas agrícolas, a partir da produção e difusão de tecnologias inspiradas nos modelos land-grant college $e^{2}$. Logo, não havia uma oferta de ensino universal, mas destinada aos filhos de fazendeiros mineiros, conforme apontava o estatuto da instituição, no ano de 1929 (Pinheiro, 2016).

Dessa maneira, analisar os argumentos que perpassam as ações afirmativas em uma universidade federal, cujo histórico é marcado por um perfil voltado às elites, implica trazer elementos para compreender os embates referentes às concepções de justiça em um contexto de possíveis disputas de narrativas e de mudanças no status quo.

\section{ORIGEM DA MERITOCRACIA ENQUANTO JUSTIÇA FORMAL}

A etimologia de mérito designa do latim meritum para tratar de ganho, lucro, pena ou castigo. $\mathrm{O}$ conceito, em sua origem, supõe a medição de algo pelo merecimento, estima ou apreço (Walzer, 2003). Assim, o indivíduo que apresenta um conjunto de atributos e valores morais, possui o mérito da recompensa ou da punição.

Entretanto, a partir das sociedades contemporâneas, o conceito passou a adotar outra roupagem, referindo-se exclusivamente às boas ações de um indivíduo e seus atributos pelo talento, conhecimento, inteligência e esforço para um trabalho (Ruschel e Valle, 2010). No campo da ciência política, o termo foi utilizado pela primeira vez por Young (1958), no ensaio "The rise of Meritocracy"3, para tratar das pessoas que adquirem um status em função do coeficiente intelectual.

Do ponto de vista histórico, essa concepção resgata os ideais do século XVIII, período em que se inicia a busca pela proteção das liberdades individuais. As revoluções Americana e Francesa instauraram uma ruptura no nepotismo e nos direitos herdados das sociedades monárquicas. Não mais o sangue definiria o lugar do indivíduo no mundo, mas os talentos e as capacidades individuais (Ochoa e Orbeta, 2017).

Logo, a meritocracia é um sistema social, político e econômico em que os privilégios são obtidos pela capacidade de cada um de realizar determinada coisa e de se posicionar em uma hierarquia baseada nos talentos ou esforço pessoal (Vieira et al., 2013). Do ponto de vista 
ontológico, parte-se de uma visão individual e igualitária dos sujeitos: todos os homens nascem iguais e livres, são propriedades de si, portanto, livres para se desenvolverem sem limitação externa; o único obstáculo é a falta de vontade (Herrera, 1995).

Quanto aos seus valores morais, propõe-se a construção de um modelo jurídico-formal segundo a qual, a lei, genérica e abstrata, deve ser igual para todos, sem qualquer distinção ou privilégio. $\mathrm{O}$ aplicador deve fazê-la incidir de forma neutra sobre as situações jurídicas concretas e conflitos interindividuais. Assim, o modelo proporciona mais justiça do que outros sistemas hierárquicos, já que possibilita a oportunidade de os indivíduos competirem entre si (Gomes, 2003).

Portanto, a hierarquia desejável e legítima é a que classifica os indivíduos exclusivamente pelo talento e capacidade no desempenho de suas tarefas. Quanto à diferença, é reconhecida, legitimada e percebida como o resultado do diferencial da aptidão inata. Mais ainda, é positivamente valorizada, pois exprime a essência de cada um, enaltecendo o indivíduo como personalidade única (Barbosa, 1996).

No ápice desse ideal, as provas, os exames, os concursos, os vestibulares possibilitam a oportunidade dos candidatos que concorrem às vagas. Logo, a escola assume um papel central de fomentar a meritocracia a partir de um conhecimento igual para todos os estudantes, em que as origens sociais não têm maior valor (Ochoa e Orbeta, 2017).

A partir das sociedades republicanas, a universalização da educação se apresenta como a fórmula justa da igualdade de oportunidades. E, ao garantir o acesso igualitário no espaço de competição por diplomas, o sistema meritocrático propõe anular a desigualdade das condições sociais (Ruschel e Vale, 2010). Configura-se o ideal de ascensão social, a partir do lema de que todos possuem as mesmas chances (oportunidades) e, assim, podem alcançar o topo, desde que se esforcem e façam a diferença no processo de competição escolar (Dubet, 2005).

\section{LIMITANTES DA MERITOCRACIA NO SISTEMA DE EDUCAÇÃO}

Mesmo com os avanços do mérito no combate às formas de poder tradicional (nepotismo, patriarcal, sanguíneo), o sistema silencia, em seu interior, outras formas de desigualdades. Assim, ao assumir a 
igualdade de oportunidades a partir de talentos e aptidões dos indivíduos, os detentores de uma cultura dominante, que geralmente são os mais familiarizados com os códigos culturais, sociais e políticos, tendem a manter as posições sociais em que se encontram.

Os sujeitos não chegam desprovidos de conhecimento, uma vez que adquirem desde a infância uma determinada bagagem cultural e um modo de valorar a cultura que incide no desempenho individual. Dessa forma, o discurso da meritocracia mascara uma reprodução social e mantém uma ordem que prima as desigualdades sociais (Bourdieu, 1996).

No caso específico do sistema escolar, a reprodução das relações de classe é o resultado de uma ação pedagógica que não parte de uma "tábula rasa", senão que exerce sobre os sujeitos que receberam de sua família ou das ações pedagógicas procedentes, uma educação primeira, capital cultural, que os diferenciam dos demais (Bourdieu, 1996).

Por efeito, se o sistema silencia as desigualdades preexistentes, ele também atribui ao estudante a responsabilidade pelo êxito ou fracasso, já que desconsidera as dimensões ligadas a sua origem econômica e social. Nos vestibulares, esse sistema ainda realiza a separação e "eleição" dos "eleitos". Ao separar os candidatos pelo exame, realiza-se o "milagre da eficácia simbólica". Os dispositivos são considerados como "provação", o que faz com que a competência técnica se traduza em competência social (Bourdieu, 1981). O exame de vestibular caracteriza-se, portanto, por um rito de passagem, de consagração, de legitimação, constituindo no resultado de uma dupla operação institucional, que integra e elimina ao mesmo tempo (Ruschel e Valle, 2010).

No Brasil, das 50 milhões de matrículas da Educação Básica, 83,5\% (aproximadamente 42 milhões), foram efetivadas em instituições públicas (Batista, 2015). No entanto, essa proporção é inversa quando se trata da Educação Superior. Os dados do Censo da Educação de 2016 indicam que as matrículas se concentram nas instituições privadas, com mais de seis milhões de estudantes, enquanto o setor público absorve apenas um milhão e novecentos mil (Paula, 2017). 
Quanto ao número de instituições, registram-se 2.111 instituições privadas, enquanto no setor público são 296 instituições (INEP, 2016). Em termos percentuais, $88 \%$ são privadas e apenas $12 \%$ públicas, demonstrando o caráter privado da educação superior brasileira, mesmo com as políticas de ampliação da rede pública nas últimas décadas (Corbari, 2018).

Se o ensino superior público continua aberto para poucos, isso é ainda mais acentuado no caso dos estudantes negros. No ano de 2018, 55,8\% dos brasileiros denominavam-se pretos ou pardos, o que colocou o Brasil como a segunda maior população negra do mundo, atrás apenas da Nigéria (IBGE, 2018).

Entretanto, mesmo com adoção das políticas de cotas que contribuiu para a recente marca histórica de 50,3\% dos estudantes negros em instituições públicas de ensino superior, a distribuição racial no ensino superior ainda é reveladora de um quadro desigual. Segundo dados do IBGE (2018), 51,5\% dos estudantes brancos com ensino médio completo ingressaram no ensino superior, enquanto esse percentual entre estudantes negros na mesma condição é de 33,4\%. A desigualdade racial persiste ao analisar o ingresso no ensino superior geral: $42,7 \%$ dos brancos acessam o ensino superior, ao passo que apenas 29,1\% dos estudantes negros lograram o mesmo êxito.

Logo, por tratar-se de um sistema seletivo e excludente, o que fazer com os perdedores na competição meritocrática? Pode-se dizer que são sujeitos de direitos, se estão excluídos da competição pela distribuição do conhecimento, antes mesmo de finalizar o tempo de escolaridade obrigatória? Em busca de alternativas para tal contradição, emergem as teorias da justiça substantiva, que fundamentarão as ações afirmativas (Ribeiro, Araújo e Tomasi, 2010).

\section{JUSTIÇA SUBSTANTIVA E AS POLÍTICAS DE COTAS}

Em contraponto ao ideal meritocrático, as teses igualitaristas valorizam o peso da origem social sobre o mérito e, portanto, admitem a necessidade de tratar da distribuição e redistribuição. Ao assumirem a equidade como categoria, parte-se do pressuposto ontológico de que o indivíduo não pode existir com as capacidades de julgamento e de expressar seus talentos de forma independente da vida social que the permitiu (Habermas, 1997; Rawls, 1997; Mouffe, 2005). 
Um dos maiores expoentes dessa forma de justiça é o filósofo John Rawls (1997), que destina críticas à concepção de talento como mérito. Aptidões não são, para ele, algo independente da sociedade. Mesmo quando instituições como a escola estão organizadas para a expressão dos potenciais dos indivíduos, não há como dizer, de maneira justa, que alguém merece mais, pois não é possível avaliar quem tem mais talentos naturais, sem considerar os arranjos sociais em que estão inseridos.

Do ponto de vista moral, move-se para a construção de um aparato jurídico-formal substantivo, que envolve dois princípios: (a) liberdade e igualdade democrática entre todos os membros; $\mathrm{e}(\mathrm{b})$ tolerância às desigualdades sociais e econômicas que resultem em benefícios para o conjunto da sociedade, ligadas a posições de oportunidades e igualdade de condições.

John Rawls (1997) procura conciliar o princípio da igualdade jurídica de oportunidades com o princípio distributivo. O conceito de igualdade considera que a desigualdade deve ser tratada de maneira específica, a fim de minimizar os abismos entre os indivíduos. Logo, as ações corretivas ou reparadoras do Estado justificam-se quando há necessidade de equacionar assimetrias entre os grupos (Neves e Lima, 2007).

Em complemento à tese distributiva, Nancy Fraser $(1995,2002)$ aborda a importância de se considerar o reconhecimento para a constituição de uma justiça substantiva. Para a autora, a desigualdade não se limita às dimensões materiais, pois perpassa também questões culturais, enquanto uma luta política.

Essa categoria é relevante para pensar a justiça, na medida em que a injustiça se radica nos padrões sociais de representação, interpretação e comunicação. Suas formas incluem a dominação cultural (submissão a padrões de interpretação e comunicação); o ocultamento (invisibilidade pelo efeito de práticas comunicativas e representacionais); e o desrespeito (difamação ou desqualificação nas representações culturais estereotipadas).

O caso específico da raça no Brasil ilustra como a injustiça pode ser ao mesmo tempo material e de representação cultural. A raça se estrutura na divisão social do trabalho, marcando, desproporcionalmente, as ocupações de baixa remuneração e status pelas pessoas negras, enquanto as ocupações de remuneração mais elevada são, majoritariamente, atribuídas aos brancos. 
A divisão racial faz parte do legado histórico da escravidão, que elaborou categorias raciais para justificar formas de apropriação e exploração, constituindo os negros como uma casta político-econômica. O resultado foi uma estrutura que engendrou modos de exploração e privação especificamente marcados pela raça. Sob esse aspecto, a injustiça racial aparece como uma espécie de injustiça distributiva que clama por compensações redistributivas.

Entretanto, a raça não está somente manifesta na injustiça político-econômica, uma vez que o aspecto central do racismo é o eurocentrismo, isto é, a construção autorizada de normas que privilegiam os traços associados por ser branco. Em sua companhia está o racismo cultural, ou seja, a desqualificação generalizada de elementos codificados como negros ou oriundos de negros.

Essa depreciação se expressa em uma variedade de danos sofridos, incluindo representações estereotipadas e humilhantes dos negros, que os colocam, supostamente, como inferiores e os mantêm em desvantagem. Por isso, a relevância de se combaterem não só as injustiças materiais através da redistribuição, como também as injustiças de reconhecimento dos grupos especificamente desvalorizados (Fraser, 1995).

É a partir da perspectiva de justiça substantiva, portanto, que as Políticas de Cotas se fundamentam na concretização do princípio constitucional da igualdade material e na neutralização dos efeitos da discriminação racial, de gênero, de idade, de origem nacional e de compleição física (Neves e Lima, 2007).

Dessa forma, as cotas representam o reconhecimento social do déficit educacional na sociedade quanto ao cumprimento do direito à educação (Batista, 2018). As políticas afirmativas são medidas para garantir a oportunidade de acesso dos grupos discriminados, ampliando a participação em diferentes setores da vida econômica, institucional, cultural e social. As ações têm por objetivo mitigar práticas discriminatórias dirigidas a grupos sociais, historicamente excluídos, cujos reconhecimento e prestígio sociais sejam baixos (Marques, 2018).

Embora comumente associada aos Estados Unidos, as cotas foram aplicadas pioneiramente na Índia, durante a década de 1950, quando o país estabeleceu nas legislaturas, no emprego público e no ensino 
superior a reserva para as castas menores da sociedade. A modalidade de política pública entrou em cena quando a legislação de orientação universalista se revelou impotente para resolver problemas derivados da persistência de padrões sociais de exclusão e discriminação ao longo do tempo (Feres Jr. e Daflon, 2015).

No Brasil, a Constituição de 1988 reconheceu, pela primeira vez, direitos coletivos como o direito à terra para populações indígenas e quilombolas. A Constituição brasileira, no artigo quinto - que trata dos direitos fundamentais - discorre sobre o sentido de igualdade (isonomia) em dois momentos: a igualdade formal perante a lei e a igualdade substantiva. Com esses reposicionamentos, a igualdade passa a ser vista no seu aspecto material e não apenas formal (Caregnato e Oliven, 2017).

O tratamento isonômico às partes significa tratar igualmente os iguais e desigualmente os desiguais, na exata medida de suas desigualdades. Assim, se estabelece uma correlação ou um fundamento racional afinado com os valores da Constituição, como prevê o terceiro critério, que não busca apenas uma igualdade material, mas a isonomia material (Santana, 2010).

Nesse sentido, as ações afirmativas não impossibilitam que o indivíduo expresse seus talentos e aptidões. O princípio da igualdade de oportunidades não é anulado, pois pressupõe a preservação da mobilidade social (todas as classes têm a liberdade de participar do jogo), bem como, contempla, em parte, o mérito (todo cotista precisa realizar uma prova e ser aprovado para ingressar na instituição). A diferença, no entanto, é que há também a intenção de minimizar as diferenças preexistentes, herdadas por determinados grupos, em comparação àqueles indivíduos de menor capital econômico, cultural e político.

\section{METODOLOGIA}

O trabalho, de natureza qualitativa, buscou analisar, na percepção de professores universitários, como a ideia de justiça é manifestada no contexto da Lei de Cotas, bem como suas relações com os argumentos contrários e/ou favoráveis às cotas. A coleta de dados ocorreu a partir de entrevistas semiestruturadas realizadas em 13 cursos de graduação da Universidade Federal de Viçosa, campus sede, no período entre novembro e janeiro de 2017. 
A instituição fica situada em Viçosa, Minas Gerais, cidade que possui 72 mil habitantes, somados à população flutuante de 20 mil pessoas. A Universidade possui 11.367 alunos matriculados na graduação e 2.853 na pós-graduação, e dispõe de 1.018 docentes distribuídos em 47 cursos de graduação e 44 programas de pós-graduação (UFV, 2018).

A primeira política de reserva de vagas adotada pela UFV foi a "Lei do boi" (Lei n 5.465 de 3 de julho de 1968). A lei determinava uma reserva de $50 \%$ das vagas nas instituições de ensino agrícola para agricultores ou filhos de agricultores e para residentes de áreas rurais. Em 1985 a "Lei do boi" foi revogada (Henrique e Lacerda, 2016).

Uma segunda política de reserva de vagas foi implantada em 2009. Na oportunidade, o Conselho Universitário (Consu) decidiu oferecer um bônus de $15 \%$ às notas obtidas no vestibular para quem tivesse cursado os 11 anos do ensino básico em escolas públicas. Esse segundo modelo foi retirado com a promulgação da Lei 12.711, em 2012, que determinou a reserva de 50\% das vagas em Instituições de Ensino Superior (IES) federais para os estudantes cotistas.

Dentro da perspectiva do recorte metodológico, a amostragem foi definida a partir de uma estratificação dos cursos com base na relação entre o desempenho de estudantes cotistas e não cotistas, realizada anteriormente por uma investigação quantitativa. O recorte buscou contemplar tanto os cursos com maiores discrepâncias de desempenho acadêmico, como aqueles em que os desempenhos foram similares. Os docentes entrevistados, foram selecionados de 13 cursos, perfazendo quatro grandes áreas do saber (Ciências Exatas e Tecnologia, Ciências Humanas, Ciências Agrárias, Ciências Biológicas e Saúde), gerando um total de 26 entrevistas, sendo 2 em cada curso selecionado.

Ressalta-se que os fragmentos textuais e as análises realizadas não remetem à origem acadêmica dos emissários, ou seja, não foram associadas aos cursos e áreas aos quais os entrevistados estavam vinculados ${ }^{4}$. Essa escolha se justifica tanto para manter uma conduta ética, quanto por não ter sido encontrado nenhum padrão de resposta e/ou posicionamento relevante que merecesse uma análise específica das diferentes áreas do saber da instituição. 
Quadro 1

Caracterização dos professores entrevistados

\begin{tabular}{ll}
\hline Entrevistado & Caracterização \\
\hline P1 & Professor/Coordenador do centro de ciências exatas. Há 10 anos na instituição. \\
\hline P2 & Professor do centro de ciências exatas. Há 6 anos na instituição. \\
\hline P3 & Professor/Coordenador do centro de ciências exatas. Há 12 anos na instituição. \\
\hline P4 & Professor do centro de ciências exatas. Há 27 anos na instituição. \\
\hline P5 & Professor/Coordenador do centro de ciências exatas. Há 20 anos na instituição. \\
\hline P6 & Professor do centro de ciências exatas. Há 28 anos na instituição. \\
\hline P7 & Professor do centro de ciências exatas. Há 28 anos na instituição. \\
\hline P9 & Professor do centro de ciências exatas. Há 40 anos na instituição. \\
\hline P10 & Professor/Coordenador do centro de ciências humanas. Há 10 meses na \\
\hline instituição.
\end{tabular}


Para o tratamento dos dados, foi utilizada a análise de conteúdo a partir da abordagem de Bardin (2011), respeitando as três etapas de análise: a pré-análise, que consistiu em sistematizar os dados, tornando as ideias iniciais operacionalizáveis; a exploração do material, que incidiu em operacionalizar as categorias, organizando os dados brutos de acordo com as categorias de análise; e o tratamento dos dados, em que as informações adquiridas foram colocadas em evidência na análise, através de inferências e interpretações.

Após a leitura das entrevistas e a formulação dos objetivos da análise anteriormente efetuados, foi realizada a codificação/criação de categorias. Para tanto, partiu-se de categorias/temas que definiram as análises dos resultados, sendo: (i) concepções de justiça nas leis das cotas; (ii) posições a favor/contrária às cotas sociais; (iii) percepções a favor/contrária às cotas raciais na ótica dos sujeitos da pesquisa.

\section{APRESENTAÇÃO E ANÁLISE DOS DADOS}

\section{Justiça formal e justiça substantiva na Lei de cotas}

Antes de adentrar no conteúdo discursivo, cabe destacar o quadro geral de posicionamento dos docentes referentes à concepção de justiça nas políticas de cotas. Observou-se que, dos 26 entrevistados, apenas seis professores (23\%) se filiaram à ideia de justiça substantiva, através da qual se avalia a desigualdade preexistente e implementam-se ações, como as cotas, para minimizar as condições díspares de competição entre os envolvidos (Gomes, 2003).

Em contrapartida, oito docentes $(30,7 \%)$ se acercaram das visões de justiça formal com base no sistema meritocrático puro, considerando, assim, que a lei de cotas não oferece a igualdade de oportunidades, já que os talentos e aptidões dos indivíduos não são respeitados plenamente (Menin et al., 2008). Por fim, o terceiro grupo, 12 professores $(46 \%)$, também se aproximou das ideias de justiça formal ao assumirem a relevância da meritocracia, estabelecendo, porém, algumas ressalvas.

Em termos percentuais, os dados indicam que a maioria dos entrevistados simpatiza com a concepção da meritocracia como um sistema em que os privilégios são obtidos pela capacidade de cada um de se posicionar em uma hierarquia baseada nos talentos ou no esforço 
pessoal (Vieira et al., 2013). Logo, assumem como pressuposto que as políticas de cotas não dão conta de atender, de forma plenamente justa, a valorização dos talentos e esforços dos candidatos nos vestibulares.

É possível notar a influência do ideal republicano burguês de justiça no imaginário desse grupo de professores. Mesmo com elevado nível de conhecimento formal, desconsideram ou silenciam, ao menos, parcialmente, as evidências históricas das desigualdades de condições na sociedade brasileira (Ruschel e Vale, 2010; Ochoa e Orbeta, 2017).

Referente ao discurso dos professores simpatizantes da justiça substantiva, os argumentos evocam o pressuposto de uma sociedade desigual e excludente, em que, primeiramente, devem ser dadas as condições de disputa iguais para todos os estudantes, para assim, considerar o processo de valoração dos talentos.

Na verdade, no meu ponto de vista é excludente, a meritocracia é definida por quem? Eu sou muito da política dos argentinos, por exemplo, vestibular, provas, meritocracia que é coisa da ditadura militar e acesso irrestrito é coisa da democracia, então, para mim essa história de meritocracia não existe. A priori, primeiro você tem que dar chance para pessoa para ver se ela tem mérito e não o contrário (P4).

Qual é o mérito? É o mérito simplesmente de um ritual de passagem? Então ele estudou, estudou para simplesmente passar na prova e passou? Tem um contexto muito maior por trás disso e que isso está sendo esquecido (P16).

$\mathrm{O}$ argumento do fragmento $\mathrm{P} 4$ ilustra similaridades com a ideia de Habermas (1997) e Mouffe (2005) a respeito da inexistência de critérios universais e essencialistas para se tratar de justiça. Os autores consideram que são necessários critérios definidos pelos membros para aceitá-los como razoáveis. No entanto, ao questionar quem os determina, já se observam os juízos de valores implícitos na concepção de justiça. Não é por menos que o significado do mérito tem mudado historicamente (Walzer, 2003; Ruschel e Valle, 2010).

Já o fragmento P16 se aproxima das ideias de John Rawls (1997), que destina críticas à concepção do talento como mérito. $\mathrm{O}$ entrevistado traz à reflexão o sentido do vestibular enquanto referência frágil, já que o ingresso via prova única de admissão não está baseado exclu- 
sivamente nas considerações isoladas dos arranjos sociais. Passar no vestibular como dimensão do sucesso não considera o peso das condições daquele candidato apto para pagar cursinhos e/ou dedicar-se mais às provas.

Quanto ao grupo de professores que se dizem favoráveis à justiça formal e, consequentemente, aos pressupostos meritocráticos, os argumentos apontam que a entrada na universidade é ou deve ser unicamente resultado do esforço individual dos estudantes, uma vez que a dedicação aos estudos é imperativa.

Eu acho que hoje é muito mais fácil entrar pelas condições do que por mérito, isso é fato, porque se você vê o Enem propriamente dito e tudo mais, antigamente era vestibular, era muito mais difícil, era na raça que você brigava por uma vaga, né, então você sabe bem como era, né, era bem difícil. Mas eu acho que hoje é mérito dos alunos, porque realmente ainda é público, é por garra e luta que você entra na universidade, ninguém vai te colocar lá, só se você quiser entrar, tem que lutar por aquilo. Mas eu acho que o mérito hoje em dia tá menos do que antes (P2).

Eu particularmente, o meu pensamento quero deixar bem claro que é em função da minha vida, o que minha vida foi. Eu sempre gostei de estudar, então começa por aí. Desde pequenininha, meus pais nunca pediram para eu estudar. Então eu acho que é muito fácil para essa pessoa que gosta de estudar entrar pelo mérito. Então se você perguntar, meu entendimento é mérito. (...) Mas aí eu paro e penso "Gente, mas e aquele com um pouco mais de dificuldade?". Aí eu falo "Ah, ainda bem que isso não é problema de todo mundo". Nossa Senhora. É muita confusão isso. Mas eu sempre gostei de estudar então tudo o que eu consegui na minha vida foi por estudo (P15).

As falas de P2 e de P15 evidenciam a recorrência da trajetória de vida para legitimar seus posicionamentos. No primeiro fragmento, sustenta-se a ideia de que os processos estruturados por meio dos vestibulares tradicionais eram mais exigentes, mais complexos, por consequência, mais meritocráticos. No segundo fragmento, as escolhas e características da entrevistada são tomadas como referência para ilustrar a superação e a conquista, como constituição da meritocracia. As passagens reforçam a ideia de preceitos baseados puramente nos talentos e capacidades individuais para justificar o desempenho em determinadas 
tarefas. Portanto, assume-se que a única hierarquia legítima é a que classifica os indivíduos exclusivamente pelo resultado do diferencial da aptidão inata (Barbosa, 1996).

Em outro fragmento da entrevistada P15, percebe-se novamente o uso de casos de sucesso, reforçando, porém, uma conjuntura na qual o indivíduo estaria separado da sociedade, no sentido de que o ambiente socioeconômico e cultural de onde vem não tem relação com o que ele pode angariar.

E aí se depende muito de mérito, se a pessoa conquistar aquilo e entrar. Então eu acredito nisso. Aí na minha casa meu esposo estudou a vida toda em escola pública, a vida toda, e ele entrou na faculdade né. E sem cota, porque não tinha cota né, e ele entrou. Fez administração aqui na UFV, depois ele fez o mestrado em administração, tudo por mérito. Aí isso ratifica ainda mais meu pensamento (P15).

O excerto, além de enaltecer o esforço do estudo daqueles sujeitos na conquista da vaga em um vestibular concorrido, como o da UFV, não identifica as dimensões subjetivas que perpassaram o indivíduo analisado. Parte-se da visão ontológica da justiça formal, em que todos os homens nascem iguais e, portanto, são livres para desenvolverem seus talentos, sem limitação externa (Herrera, 1995).

Com base nos argumentos dos entrevistados, é possível perceber que a política de cotas ilustra distintas concepções de justiça, que, no entanto, reproduzem, na maioria dos docentes, os ideais de valores ligados ao mérito, de forma a defender que todos possuem capacidades iguais para obter sucesso. Desconsideram-se as desigualdades sociais históricas que atribuem privilégios de classe; rejeitam-se, ainda, os conflitos em um sistema tradicional de seleção excludente e injusto, que deixa de fora, em sua maioria, aqueles com menos capital econômico, cultural e político (Bourdieu; 1981, 1996; Menin et al., 2008).

\section{Sobre os argumentos favoráveis e contrários as cotas sociais}

A segunda parte da pesquisa buscou compreender a posição dos docentes no que se refere às cotas sociais, ou seja, aquelas destinadas exclusivamente para os estudantes de menor poder aquisitivo e oriundos de escolas públicas. Em termos gerais, os resultados apontaram 
que, para 65\% dos professores (17 docentes), a ação compensatória é justificada como satisfatória, enquanto $15 \%$ (quatro docentes) não assumiram uma opinião formada e 19\% (cinco professores) foram contrários às cotas sociais.

Os dados sinalizam que, apesar de uma aproximação de um ideal de meritocracia (conforme registrado no tópico anterior), a maioria dos entrevistados não nega a importância, temporária e parcial, das políticas de cotas sociais. Os achados não destonam da realidade nacional; em recente pesquisa realizada pelo jornal $O$ Estado de S. Paulo, no ano de 2017, 77\% dos brasileiros declararam ser favoráveis às cotas sociais, de um total 2.002 entrevistados pelo país (Guia do Estudante, 2017).

Quanto aos argumentos dos docentes favoráveis às cotas sociais, destacam-se como pano de fundo as condições históricas às quais os cotistas foram submetidos. Evidencia-se o caráter paliativo, na medida em que corrige as defasagens do ensino público de base.

Eu acho que a cota é um mal necessário, tem que ter, principalmente acho que é uma maneira paliativa (P3).

Para mim a política afirmativa tem que ser feita para minorar, mitigar as desigualdades sociais que o Brasil tem, que foram geradas ao longo da nossa história. Isso aí para mim ainda é inevitável, tem que ter e tinham que ser muito mais disseminadas em todas as áreas essas políticas afirmativas (P4).

É possível perceber, nos discursos, a defesa das cotas sociais como uma tentativa de democratizar o ingresso dos estudantes nas universidades, as quais eram ocupadas, até então, por uma elite detentora de alto poder aquisitivo e, em sua maioria, branca. Logo, os argumentos dizem respeito não apenas à possibilidade de entrada no ensino superior público, como também a um mecanismo de redução das desigualdades sociais, a partir do aumento da qualificação para a inserção no mercado de trabalho (Souza e Brandalise, 2011).

Ainda sobre a democratização do acesso ao ensino superior, o entrevistado P4, há 27 anos na instituição, destacou que foi notório o aumento da diversidade social no ambiente acadêmico. 
Percebo que a política de cotas está funcionando. Eu vejo muitas pessoas diferentes na universidade que eu não via quando eu entrei aqui. Uma universidade branca, classe média de mauricinhos, e hoje você vê uma variedade muito maior de pessoas de todas as feições na universidade, muitas pessoas eu conheço assim, particularmente, que vêm do campo, lá da roça, que vêm das classes mais empobrecidas. $E$ as pessoas que possuem menor renda têm o maior esforço para agarrar essa oportunidade única para eles. É importante isso, enquanto que a maioria dos brancos e arrumados, a universidade é só um ponto de passagem para pegar o canudo e depois permitir que eles entrem no mercado com uma boa condição. Aumentou a quantidade de negros, mulheres, as minorias, indígenas... você vê gente aí, pessoas com opções sexuais diferentes... então, o meio ambiente mudou completamente e não tem nenhum ponto deletério no rendimento acadêmico, no meu ponto de vista não tem nenhum (P4).

O entrevistado imputa às universidades um significado que recobra a coisa pública como algo que deve estar em posição de acolher os diversos grupos da sociedade. Desse modo, as universidades não seriam mais ocupadas somente por uma classe média branca e urbana, mas inserindo grupos historicamente ausentes nesses espaços.

As percepções do docente no fragmento $\mathrm{P} 4$, ainda que baseadas numa empiria, possuem fundamento, já que dados da Associação Nacional dos Dirigentes das Instituições Federais de Ensino Superior (Andifes, 2019) apontam que, até o final de 2018, o perfil dos estudantes das 63 universidades federais do país mudou, a partir da implementação das políticas de cotas e assistenciais. Registrou-se que 70,2\% dos estudantes das instituições públicas possuem uma renda mensal familiar per capita de até um salário e meio. Destes, 37,9\% vivem com até meio salário, $38,4 \%$ com mais de meio a um salário e $23,7 \%$ com mais de um a um e meio salário.

Fenômeno semelhante ocorreu nos Estados Unidos nos últimos 40 anos. Durante o período de 1960 a 2000, os dados mostraram um aumento significativo da população pobre e negra ingressante na educação superior. A porcentagem de negros matriculada passou de 13\% em 1967 para 30,3\% em 2000. Uma hipótese que estabelece a correlação positiva do aumento de negros em virtude das ações afirmativas se baseia no fato de que, entre 1961 e 1966, antes da difusão de programas afirmativos, o número de negros no ensino superior 
permaneceu praticamente o mesmo. Já no período da implementação, houve um grande crescimento; entre 1967 e 1976 praticamente dobrou a porcentagem daqueles ingressantes.

Esses movimentos podem ser vistos sob diferentes prismas. De maneira mais concreta, alargam as possibilidades de redução - de maneira sustentável - da desigualdade social histórica imposta a pobres e negros. Ademais, contribuem para a transformação das próprias instituições de ensino, historicamente brancas. Se a legitimidade inerente às cotas para estudantes de escolas públicas pode soar inconteste, em razão do reconhecimento da precariedade do ensino público e da necessidade de ajuste social, a mesma legitimidade é por vezes questionada quando recai sobre as reservas de vagas destinadas a pretos, pardos e indígenas.

Fraser (2002) destaca que a centralidade das pautas de grupos variados é representativa da transição dos questionamentos do eixo da classe para outros eixos de subordinação. Em outros termos, a substituição das lutas de redistribuição por lutas de reconhecimento constitui uma concepção bidimensional da justiça social.

A fala de P4 remete diretamente ao que Fraser $(1995,2002)$ considera uma terceira dimensão necessária, a representação. A política de cotas direcionada aos estudantes de baixa renda, dentre eles, pretos, pardos e indígenas, não apenas confere o exercício político da permanência no ensino superior e do ser visto pelo reconhecimento, mas também implica a redistribuição, conferindo capacidade de enfrentamento direto às injustiças de má distribuição, não reconhecimento e má representação.

Quanto aos argumentos dos professores contrários às cotas, os discursos se situam em duas vertentes. A primeira diz respeito às cotas como forma de mascaramento das deficiências do ensino público de base, na medida em que premia estudantes que poderiam não ter acesso ao ensino superior sem as mesmas.

Eu acho que a cota é desnecessária, pelo seguinte: é uma forma de discriminação muito grande, no sentido ruim da palavra. A criação de cotas, a meu ver, é uma forma de maquiar a defasagem do ensino médio. Então se o ensino público é sucateado hoje, que é o que tá caminhando para acontecer com as universidades também, o ensino fundamental e médio, 
uma vez sucateado, não dá condições para um estudante de escola pública entrar em uma universidade em pé de igualdade com os estudantes de ensino particular (P23).

O fragmento extraído da fala de P23 sinaliza que as cotas mascaram a necessidade de melhoria no ensino básico, portanto, assumem um caráter estritamente paliativo. Quando o entrevistado ressalta que o sucateamento do ensino básico pode atingir o nível superior, o faz estabelecendo uma relação direta com a entrada dos cotistas nas universidades, dado que "um estudante de escola pública não entra em pé de igualdade com os estudantes de ensino particular". Nesse posicionamento prevalece o caráter meritocrático, na medida em que as universidades deveriam ser ocupadas por estudantes que apresentam os maiores desempenhos nos processos seletivos.

Chama a atenção o fato de o entrevistado fundamentar sua argumentação sem a utilização de dados empíricos, semelhante ao que ocorreu no início dos debates no país há 16 anos. A fragilidade dos argumentos é evidenciada quando comparada com os estudos empíricos que, desde 2004, trazem evidências de que os cotistas não só têm acompanhado os demais colegas, como ainda abandonam menos e, em muitos casos, colam grau em maior percentual (Brandão e Matta, 2007; Bezerra e Gurgel, 2011; Silva e Pacheco, 2013; Moreira Silva, 2017; Corbari, 2018; Arrigoni, 2018).

Um segundo argumento visa deslegitimar as cotas pelo prisma do preconceito. O posicionamento contrário diz respeito - mas não somente - a uma hipotética discriminação que os cotistas (mesmo brancos) podem sofrer em razão de uma parcela das vagas ser reservada para eles.

Porque eu não fiquei muito satisfeita (...). Porque no início as cotas começaram bem pequenininhas (...) e eu descobri, não sei se é verdade, que agora $50 \%$ é cota. E então só sobraram 20 vagas em [nome do curso foi retirado]. Olhando agora para o meu próprio umbigo, olhando para minha filha, que hoje tem 12 anos. Então minha filha não tá mais brigando por 40, minha filha agora tá brigando só por 20. Aí eu parei pra pensar e falei assim: nossa, acho que a discriminação tá invertendo né?! Eu acho que o negócio vai chegar a um ponto, se esse negócio continuar desse jeito, que os brancos serão discriminados. Você vai ser discriminada porque teve condições de estudar a vida toda numa escola particular, você vai ser discriminado porque você é branca. Parece assim que frase mais absurda. (...) E se me perguntar: será que isso é justo? A nossa família que está sendo 
prejudicada porque a gente tem condição financeira melhor, né. Aí se você pensar bem: nossa, sua vida é muito melhor. É, é muito melhor, isso eu não vou negar, não estou negando. Como falei desde o início eu sou privilegiada. Agradeço a Deus todos os dias. Mas tudo foi conquistado. Para entrar aqui eu fiz concurso, fiz prova. Então tudo o que eu tenho hoje foi fruto de estudo (...). Por exemplo, eu não sou negra então não sei o que eles passam, não sou pobre, não sei o que eles passam. Então é muito difícil. O que eu sei? O que eu sei é que eu sou uma privilegiada, isso eu já sabia, que eu era privilegiada (P15).

Subentende-se, aqui, a não necessidade de cotas, em razão de uma capacidade social igualitária entre os envolvidos, desconsiderando, todavia, o elemento concreto e simbólico que permeia o sistema escolar anterior (Castro e Stamm, 2016). Da mesma forma, a tese de que as cotas têm estabelecido um fenômeno de discriminar os beneficiários carece de fundamentação teórica e empírica. Historicamente, o que se observa é que a discriminação está presente nas relações sociais e é reproduzida para dentro dos sistemas de competição, como os vestibulares.

Não por coincidência, logo após o fim da escravidão, o Estado brasileiro apostou em uma estratégia de "branqueamento" da população, adotando uma política de imigração europeia em massa. Se o alvo a ser alcançado era uma população branca e se a situação devia ser modificada exatamente por conta da população negra, a essa última foi atribuída uma dupla discriminação: uma, decorrente da herança das condições materiais; outra, de representação, marcada pelo estereótipo do atraso e da inferioridade (Brandão e Marins, 2007).

\section{Cotas raciais: perspectivas em $\mathrm{jog} 0^{5}$}

Outro ponto da pesquisa diz respeito, especificamente, às cotas raciais. Observou-se, na ótica dos professores, que 57,6\% (15 docentes) se disseram favoráveis às ações afirmativas dessa natureza, 15,3\% (4 docentes) não apresentaram opinião formada e 27,0\% (7 docentes) mostraram-se contrários.

Os dados apontam para dois fenômenos a serem analisados. O primeiro é que o quadro de professores, em sua maioria, compartilha das políticas de cotas de natureza social e racial. Ao considerar que esses docentes trabalham em uma universidade federal do interior de 
Minas Gerais, cujo perfil, historicamente, era voltado para a formação agrária de uma elite mineira, há mudanças nesse grupo institucional, ao menos de parte do grupo de professores.

O segundo aspecto a ser observado é que, mesmo sendo a maioria favorável às cotas raciais $(57,6 \%)$, os números são inferiores àqueles favoráveis às cotas sociais $(65 \%)$, conforme registrado no tópico anterior. Os dados indicam que a sensibilidade às questões raciais se apresenta como um desafio maior do que as discrepâncias de ordem social.

No que se refere aos argumentos favoráveis às cotas, assumem as mesmas como fonte de ajuste de uma dívida histórica, na medida em que o processo de formação da raça negra no país é necessariamente um processo de exploração.

As cotas, eu acho que existe certamente um erro quando dizem que as cotas devem ser provisórias. Eu acho sim, que devem ser provisórias. Aí você me pergunta: mas você não falou que é um erro? Mas que as cotas durem 500 anos, porque esse foi o tempo em que várias classes de pessoas foram impedidas, e o principal foram os negros, uma escravidão que durou uma eternidade, então para que haja um resgate de todo esse povo: índios, negros... (P8).

Nesse excerto é possível perceber o caráter reparatório e inclusivo das cotas raciais. Sobre o caráter reparatório, entende-se que as cotas contemplam grupos que sofreram e sofrem discriminação, sendo necessário criar mecanismos de inserção desses indivíduos em espaços historicamente de exclusão. Nesse sentido, é recorrente, nas falas dos entrevistados favoráveis às cotas, a busca por igualdade de condições, sintetizado pelo fragmento "eu concordo que todos os setores excluídos têm que ter políticas afirmativas, para garantir igualdade e oportunidade de um nicho" (P4).

As ações afirmativas são vistas, também, como uma forma de reparação dos danos causados a gerações e gerações de negros que foram escravizados por séculos e abandonados à sua sorte após a abolição pelo Estado brasileiro, que, ao doar terras aos imigrantes europeus, favoreceu esses grupos recém-chegados, em detrimento da população negra brasileira (Oliven, 2007). 
A respeito dos entrevistados contrários às cotas raciais, o principal argumento é que os negros possuem a mesma capacidade intelectual dos brancos e, portanto, a utilização de cotas para eles seria um privilégio para um determinado grupo.

Porque eu não posso chamar um negro de burro, o negro é uma pessoa normal, então assim ele é uma pessoa normal (...). Mas esse negócio de negro para mim não cola não. Cor de pele não pode diferenciar ninguém. Essa é minha opinião né (P13).

A fala supracitada remete à negação da ideia de raças como argumento para que nenhum dos lados tenha vantagens nas políticas públicas. Não há dúvidas a respeito da viabilidade do uso do termo raça quando aplicado à espécie humana, já que o número de genes responsáveis por características como cor de pele, espessura do cabelo, formatação do nariz, corresponde a aproximadamente $0,00005 \%$ da carga genética total. As características fenotípicas são ainda sujeitas a sofrerem influências do meio. Assim, diferenças apresentadas pelas diversas etnias não passam de meras situações culturais a que cada etnia se viu exposta (Pena e Bertolini, 2004).

No entanto, ao não reconhecer a existência de discriminação pela cor da pele, o argumento nega os privilégios da raça branca e, por consequência, suprime a necessidade de uma política reparadora. $\mathrm{O}$ caráter seletivo com o qual a questão é tratada se estende quando outros espaços são tomados como referência para deslegitimar a reserva de vagas para negros. A fala de P24 dialoga com essa perspectiva, na medida em que entende que a segregação não ocorre em outros espaços, como nos restaurantes.

É o racismo declarado né?! Não é porque a pessoa tem uma pele mais escura que ela tem mais direito ou menos direito. No Brasil não existe restaurante para negro, restaurante para branco. Morei nos Estados Unidos. Eu sei o que é racismo real (P24).

$\mathrm{O}$ argumento parece ter suas raízes nos debates iniciais das políticas de cotas, sob a influência das ideias de Maggie e Fry (2004). Para os autores, a tradição brasileira é diferente da realidade americana, já que estabelece uma identidade nacional do mestiço como um mecanismo de combate à polarização do racismo presente em outros países. Nesse 
sentido, sustentam que a implantação das cotas raciais pode corroer uma suposta identidade nacional e operacionalizar a racialização baseada na identidade binária de brancos versus negros.

Apesar do exposto, ao investigar as manifestações de preconceito no país, a pesquisa realizada pelo Instituto Data Popular constatou que 92\% dos brasileiros reconheciam a existência de preconceito racial. Entretanto, apesar da consciência de um preconceito generalizado, só 1,3\% admitiam serem preconceituosos (Correio Braziliense, 2014). Assim, conforme ilustra Domingues (2005:165), ao discorrer que "o Brasil é o país da segregação racial não declarada", nega-se a exploração sofrida pelas minorias (no sentido político) raciais.

Da mesma forma, esse tipo de argumento que relativiza a historicidade e o racismo presente no país pode ser percebido novamente na fala de P15.

A [cota] por cor que não acho legal, sabe por quê? No meu pensamento eu não acho legal porque... já perguntaram para os negros se eles querem ser tratados assim? Eu não sei se eu quero chegar num lugar e ser tratado diferente por causa da minha cor de pele (...) "Maria [nome fictício], e você?". Eu, ano passado eu estava grávida, aproveitei de todos os privilégios que eu tinha, adorei, adorei. Aproveitei de tudo, era um direito meu. Mas, o que eu quero dizer, foi uma situação que me agradou muito, mas será que eu ia gostar se fosse uma situação de me tratarem diferente por conta disso, me tratar de diferente a vida inteira? Eu não sei se eu gostaria. Eu gosto muito de lutar pelas coisas que eu conquisto, e eu acho que os negros também, alguns vão falar isso (...) o motivo eu acho que acaba sendo a escravidão que realmente foi um absurdo o que aconteceu, realmente a gente tem uma dívida tremenda, eu acho que é uma forma de tentar, sei lá, pagar essa dívida. Porque é um absurdo você pensar que fazia uma pessoa como escrava, gente é impensável uma situação dessa. Mas por outro lado as pessoas falam que para aquela época era uma situação normal para uns, para outros não. Mas em relação aos negros, eu não gostaria que me tratassem diferente. Isso seria uma forma de discriminação, eu dar privilégios. Ah, eu falo que negro pode chegar atrasado. Olha que chato (P15).

De acordo com os argumentos utilizados por P15, o conteúdo implícito do fragmento remete às cotas como política que pode colocar o negro em condição de inferioridade, uma vez que assume a diferenciação inerente ao sistema de cotas como adoção de uma forma diferente de 
se olhar para o negro, nesse caso, subjugada. Para o entrevistado, a política de cotas raciais poderia prejudicar a imagem profissional dos funcionários, estudantes e artistas negros, porque eles seriam acusados de usufruir de privilégios para acessar determinadas oportunidades. Ou seja, em situações de concorrência acirrada, as cotas poderiam estimular preconceitos. Ainda, sob o pretexto de favorecer materialmente uma população desfavorecida, a política de cotas poderia prejudicar os valores mais respeitáveis: o orgulho e a dignidade da população negra.

Entretanto, o conteúdo discursivo contrapõe o orgulho e a dignidade à reivindicação de uma política compensatória numa sociedade que, por mais de 400 anos, atrasou seu desenvolvimento e o exercício de sua plena cidadania (Munanga, 2001). Assim, a reparação dos danos causados por séculos de discriminação prejudicaria efetivamente a dignidade de uma população? Teriam as minorias o receio de serem indenizadas pelas discriminações que sofreram e ainda sofrem diariamente?

\section{CONSIDERAÇÕES FINAIS}

Apesar dos significativos trabalhos que analisam as políticas de cotas nesses últimos 16 anos (Brandão e Matta, 2007; Bezerra e Gurgel, 2011; Silva e Pacheco, 2013; Moreira Silva, 2017; Corbari, 2018; Arrigoni, 2018), a literatura nacional ainda não explorou com densidade as influências das teorias de justiça, em específico, as ideias de meritocracia sobre os discursos de docentes.

Compreende-se que o recorte empírico, a partir de um grupo de professores universitários, é relevante para a área, haja vista que são atores que detêm força nas narrativas das políticas afirmativas, além de assumirem um papel central de recepção e interface com os estudantes cotistas e de ampla concorrência. Ademais, ao selecionar, como objeto de estudo, os docentes de uma instituição federal de ensino marcada por um histórico de formação para as elites mineiras, os dados da pesquisa orientam às possíveis mudanças e desafios em um contexto de disputa de narrativas.

Nesse sentido, os achados da investigação ilustram que a maioria dos docentes, mesmo considerando as políticas de cotas como uma ação satisfatória, reproduzem, em seu interior, os valores de um ideal de 
justiça formal, a partir da meritocracia. Os argumentos que sustentam a tese majoritariamente dizem respeito ao resultado como consequência de um esforço pessoal, no valor da igualdade da capacidade e de direitos.

Apesar do reconhecimento da importância das cotas enquanto mecanismo de mobilidade social, foram identificados argumentos que imputam às cotas caráter paliativo, sendo essa política algo que não apenas sublima as deficiências do ensino de base, como também poderia produzir uma perda de qualidade do ensino. Há recorrências, inclusive, do uso de casos singulares, a partir das histórias de vida, a fim de ilustrar que "o querer" poderia ser um substituto às cotas, em que o mérito, como algo localizado se torna representativo da meritocracia, anulando seus antecedentes.

As cotas raciais são objeto de maior resistência por parte dos entrevistados, os quais se apresentam mais inclinados às cotas por renda / escola pública. Os resultados apontam para a naturalização das relações quando se trata das reservas de vagas raciais, uma vez que, para confrontar a legitimidade desses grupos, recorre-se à igualdade racial pautada em seu caráter biológico. Nesse caso, prevalece o entendimento de que as cotas podem representar um privilégio restrito aos negros, estimular o preconceito racial por meio da estigmatização dos estudantes beneficiados e corroer a identidade nacional, que opera por meio de uma identidade binária na sociedade brasileira.

Pela lógica dessa justiça unicamente formal, as circunstâncias sociais em que as diferentes individualidades operaram quase nunca são explicitadas ou declinadas para fins de avaliação. Quando trazidas à baila, são para valorizar mais o desempenho individual. São utilizadas para reforçar o valor das realizações, na medida em que comprovam a superação de condições desfavoráveis, revertidas pela força da individualidade. É a prova da superioridade ontológica do indivíduo sobre o grupo social (Barbosa, 1996).

Se considerarmos que o art. 7 da Lei de Cotas, alterado pela Lei no 13.409/2016, prevê, até o ano de 2022, a revisão da ação afirmativa (Karruz, 2018), os resultados desta investigação colocam em evidência a necessidade da publicização de informações que qualifiquem e atualizem o debate, sobretudo em um contexto de ofensivas de governos conservadores contrários às políticas de cotas, neste último ano. 
Reforça-se, portanto, a continuidade de estudos que desvelem as principais mudanças após a implantação das cotas, uma vez que podem elucidar elementos subjacentes ao tratamento das ações, principalmente aqueles que se formam nas entranhas de uma sociedade com resquícios oligárquicos e escravocratas.

Por fim, se no presente preâmbulo deste artigo indagou-se quais das duas candidatas à vaga de um curso de medicina teria mais mérito, aquela aprovada ou a negra (oriunda de camadas sociais pobres) que não conseguiu a inserção, é possível afirmar que, sob uma ótica da justiça substantiva, a reflexão de Ribeiro (2003) possibilita relativizar e problematizar um pouco mais a complexidade do ideal da meritocracia, a partir dos vestibulares tradicionais:

Até o final do século XIX, mais precisamente 1872, o país registrava a existência de leis que proibiam o acesso de negros e negras, livres ou libertos, à escola de qualquer nível, lembrando que a criação dos primeiros cursos de nível superior data do início do século XIX. Daí porque não é a mesma coisa ser branco pobre e negro pobre no Brasil.

Vemo-nos diante de uma complexa e distante superação do ethos elitista que historicamente habita as Universidades Brasileiras, pois mesmo quando reconhecida a importância da lei de cotas para a redução da distorção no acesso ao ensino superior, aspectos de meritocracia são recobrados como contrapeso. As formas são diversas, se fazendo presentes ao se assumirem trajetórias pessoais como regra, ou mesmo ao reduzir a entrada de estudantes pretos e pardos à esfera socioeconômica, negligenciando o racismo estrutural manifesto, por exemplo, no exercício predominantemente branco de profissões de maior prestígio social.

(Recebido para publicação em 22 de março de 2019)

(Reapresentado em 1 de dezembro de 2019)

(Reapresentado em 13 de junho de 2020)

(Aprovado para publicação em 8 de agosto de 2020)

\section{NOTAS}

1. Como não existe um critério científico para essa classificação, acordou-se, neste artigo, utilizar a etimologia pretos para se referir aos dados de pesquisas do Instituto Brasileiro de Geografia e Estatística (IBGE) (que usa essa etimologia) e da própria descrição das políticas de cotas. Da mesma forma, o termo "negros", comumente utilizado na literatura 
e pelo próprio movimento União de Negros pela Igualdade (Unegro), será empregado para englobar a soma de indivíduos que se autodeclaram pretos e pardos.

2. Modelo de instituições de ensino superior criada nos Estados Unidos, em meados do século XIX. Localizadas em regiões rurais, o seu propósito era criar alternativas para os desafios dos fazendeiros americanos, através de práticas agrícolas que racionalizassem a produção, transformando o saber rotineiro em científico.

3. O texto era uma sátira. Young (1958) alerta que havia uma obsessão com a quantificação e resultados de testes, o que poderia gerar efeitos nocivos. No entanto, o termo foi apropriado pelos partidos de direita para descrever a possibilidade de ascensão social, em decorrência do esforço individual.

4. Por questões éticas foram retiradas as informações que pudessem comprometer a confidencialidade dos entrevistados, incluindo apenas os cursos e tempo de instituição aos quais estão associados. Desse modo, foram identificados por alfanuméricos que variaram de P1 a P26, sem, contudo, associá-los às respectivas áreas do saber a que estão vinculados.

5. O termo "cotas raciais" foi utilizado nesta seção a fim de preservar o termo comumente adotado para se designar a parcela das vagas destinada a pretos e pardos com base na Lei no $12.711 / 2012$. É necessário demarcar, aqui, alguns pontos de aproximação e distanciamento nos termos cor, raça e etnia. Sobre este último, remete a aspectos relacionados à origem e à cultura, não necessariamente homogêneas, mas que podem representar traços comuns que permitam classificação, sendo brancos, negros e indígenas as mais habituais no Brasil, decorrentes do nosso processo de colonização. Sobre o termo "raça", é possível identificar pontos de convergência e sombreamento com a etnia. Destaca-se que a nossa formação enquanto nação se daria no entrecruzamento de três raças - caucasoide, africana e americana, que por sua vez resultariam num povo homogêneo, de cultura latina. Posteriormente, tanto o caráter ideário da Revolução de 30, com sua busca por uma identidade nacional, como a conotação negativa atribuída ao termo raça impressa no Holocausto, fizeram com que o uso do termo "raça" perdesse fôlego. Todavia, a reincorporação do termo, em particular no Brasil, se legitima por ser o termo representante não apenas de movimento de afirmação e resistência de um grupo historicamente marginalizado numa sociedade, como também por ser alternativa à conotação racista impregnada no uso do termo "cor". Esses elementos fizeram o IBGE modificar, a partir de 1991, a antiga pergunta "Qual é a sua cor?" para "Qual é a sua cor/raça?". 


\section{REFERÊNCIAS}

AGÊNCIA EBC BRASIL. (2018), “Bolsonaro diz que políticas afirmativas reforçam o "coitadismo" no Brasil". Disponível em: http:/ /agenciabrasil.ebc.com.br/politica/noticia/2018-10/bolsonaro-diz-que-politicas-afirmativas-reforcam-coitadismo-no-pais Acesso em 10 de março de 2019.

ANDIFES (Associação Nacional dos Dirigentes das Instituições Federais de Ensino Superior). (2019), V perfil socioeconômico e cultural dos estudantes de graduação das instituições federais de Ensino Superior Brasileiras. Disponível em http:/ /www.andifes.org.br/wp-content/ uploads/2019/05/V-Pesquisa-do-Perfil-Socioecon\%C3\%B4mico-dos-Estudantes-de-Gradua\%C3\%A7\%C3\%A3o-das-Universidades-Federais-1.pdf Acesso em 12 de novembro de 2019.

ARRIGONI, Fernando. (2018), Gestão pública: busca da igualdade social a partir da Ação Afirmativa Cota no ensino superior brasileiro. Tese (Doutorado em Administração), Fundação Getúlio Vargas, Rio de Janeiro.

BARBOSA, Lívia. (1996), "Meritocracia à brasileira: o que é desempenho no Brasil”. Revista do Serviço Público, vol. 120, nº 3, pp. 58-102.

BARDIN, Laurence. (2011), Análise de conteúdo. São Paulo: Edições 70.

BATISTA, Neusa. (2018), “Cotas para o acesso de egressos de escolas públicas na Educação Superior". Pro-Posições, vol. 29, n³, pp. 41-65.

. (2015), "Políticas públicas de ações afirmativas para a Educação Superior: o Conselho Universitário como arena de disputas". Ensaio: Avaliação e Políticas Públicas em Educação, vol. $23, \mathrm{n}^{\circ} 86$, pp. $95-128$.

BEZERRA, Tereza; GURGEL, Claudio. (2011), A política pública de cotas em universidades, desempenho acadêmico e inclusão social. Sustainable Business International Journal, vol. 9, pp.1-22.

BOURDIEU, Pierre. (1996), La reproducción. España: Fontamara.

. (1981), "Épreuve scolaire et consécration sociale". Actes de la Recherche en Sciences Sociales. Paris, $\mathrm{n}^{\circ} 39$, pp. 3-70.

BRANDÃO, André; MARINS, Mani. (2007), “Cotas para negros no ensino superior e formas de classificação racial". Educação e Pesquisa, vol. 33, n 1, pp. 27-45.

BRANDÃO, André; MATTA, Leonel. (2007), “Avaliação da política de reserva de vagas na Universidade Estadual do Norte Fluminense: estudo dos alunos que ingressaram em 2003". In: A. Brandão (org.), Cotas raciais no Brasil: a primeira avaliação. Rio de Janeiro: DP\&A, pp. 49-80.

BRASIL. (2012), Decreto $\mathrm{n}^{\mathrm{o}} 7.284$, de 11 de outubro de 2012. Regulamenta a Lei $\mathrm{n}^{\mathrm{o}} 12.711$, de 29 de agosto de 2012, que dispõe sobre o ingresso nas universidades federais e nas instituições federais de ensino técnico de nível médio e dá outras providências. Diário Oficial da União, Brasília, DF.

CAREGNATO, Celia; OLIVEN, Arabela. (2017), “Educação superior e políticas de ação afirmativa no Rio Grande do Sul: desigualdades e equidade". Educar em Revista, n ${ }^{\circ}$ 64, pp. 171-187. 
CASTRO, Bruna; STAMM, Cristiano. (2016), Diferenças salariais de gênero e raça no mercado de trabalho brasileiro: uma análise estatística e econométrica. Anais do XX Encontro Nacional de Estudo de População, Foz do Iguaçu, 17-22 de outubro.

CORBARI, Elza. (2018), Avaliação do impacto da política de cotas na Unioeste: quem de fato foi incluído? Dissertação (Mestrado em Ciências Sociais), Universidade Estadual do Oeste do Paraná, Paraná.

CORREIO BRAZILIENSE. (2014), “Brasileiros acham que há racismo, mas somente 1,3\% se consideram racistas". Disponível em: https: / / www.correiobraziliense.com.br/app/ noticia/brasil/2014/03/25/internas_polbraeco,419288/brasileiros-acham-que-ha-racismo-mas-somente-1-3-se-consideram-racistas.shtml Acesso em 23 de maio de 2020.

DOMINGUES, Petrônio. (2005), “Ações afirmativas para negros no Brasil: o início de uma reparação histórica". Revista Brasileira de Educação, n² 29, pp. 164-176.

DUBET, François. (2005), La escuela de las oportunidades: ¿qué es una escuela justa? Barcelona: Gedisa.

FERES JÚNIOR, João; DAFLON, Verônica. (2015), “Ação afirmativa na Índia e no Brasil: um estudo sobre a retórica acadêmica". Sociologias, vol. 17, nº 40, pp. 92-123.

FRASER, Nancy. (2002), "A justiça social na globalização: redistribuição, reconhecimento e participação". Revista Crítica de Ciências Sociais, n 63, pp. 7-20.

. (1995), “From redistribution to recognition?". New Left Review, n 212, pp. 68-93.

GOMES, Joaquim. (2003), “O debate constitucional sobre as ações afirmativas”. In: R. Santos; F. Lobato (orgs.), Ações afirmativas: políticas públicas contra as desigualdades raciais. Rio de Janeiro: DP\&A, pp. 15-57.

GUIA DO ESTUDANTE. (2017), "Pesquisa lbope mostra que 62\% dos brasileiros são a favor das cotas". Disponível em: https:/ /guiadoestudante.abril.com.br/universidades/pesquisa-ibope-mostra-que-62-dos-brasileiros-sao-a-favor-das-cotas Acesso em 13 de março de 2019.

HABERMAS, Jürgen. (1997), Débat sur la justice politique. Paris: CERF.

HENRIQUE, Ana; LACERDA, Wânia. (2016), “Perfis dos universitários beneficiados pela política de ação afirmativa na UFV". Educação em Perspectiva, vol. 7, n 2, pp. 415-443.

HERRERA, Sajid. (1995), “El individualismo liberal”. Realidad, no 48, pp. 1047-1071.

IBGE (Instituto Brasileiro de Geografia e Estatística). (2018), Síntese de Indicadores Sociais: uma análise das condições de vida da população brasileira - 2018. Rio de Janeiro: IBGE.

INEP (Instituto Nacional de Estudos e Pesquisas Educacionais Anísio Teixeira). (2016), Sinopse Estatística da Educação Superior 2016. Brasília: Inep.

KARRUZ, Ana. (2018), “Oferta, Demanda e Nota de Corte: experimento natural sobre efeitos de Lei das Cotas no acesso à Universidade Federal de Minas Gerais". Revista de Ciências Sociais, vol. 61, nº 2, pp. 405-462.

MAGGIE, Yvonne; FRY, Peter. (2004), "Cotas raciais: construindo um país dividido". Econômica, vol. 6, $\mathrm{n}^{\circ} 1$, pp. 153-162.

MARQUES, Eugenia. (2018), “O acesso à educação superior e o fortalecimento da identidade negra". Revista Brasileira de Educação, vol. 23, pp. 1-23. 
MENDONÇA, Sonia. (1997), O ruralismo brasileiro (1888-1931). São Paulo: Hucitec.

MENIN, Maria et al. (2008), "Representações de estudantes universitários sobre alunos cotistas: confronto de valores". Educação e Pesquisa, vol. 34, n 2, pp. 255-272.

MOREIRA SILVA, Bruna. (2017), Desconstruindo mitos: meritocracia e a lei de cotas. Dissertação (Mestrado em Administração), Universidade Federal de Viçosa, Viçosa.

MOUFFE, Chantal. (2005), On the political. New York: Routledge.

MUNANGA, Kabengele. (2001), "Políticas de ação afirmativa em benefício da população negra no Brasil: um ponto de vista em defesa de cotas". Sociedade e Cultura, vol. 4, nº 2, pp. 31-43.

NEVES, Paulo; LIMA, Marcus. (2007), "Percepções de justiça social e atitudes de estudantes pré-vestibulandos e universitários sobre as cotas para negros e pardos nas universidades públicas". Revista Brasileira de Educação, vol. 12, nº 34, pp.17-38.

OCHOA, Monica; ORBETA, Camila. (2017), “Discursos sobre classe social e meritocracia de escolares vulneráveis no Chile”. Cadernos de Pesquisa, vol. 47, n 164, pp. 496-518.

OLIVEN, Arabela. (2007), “Ações afirmativas, relações raciais e políticas de cotas nas universidades: uma comparação entre os Estados Unidos e Brasil”. Educação, vol. 30, n 1, pp. 29-51.

PAULA, Maria. (2017), "Políticas de democratização da educação superior brasileira: limites e desafios para a próxima década”. Avaliação, vol. 22, n 2, pp. 301-315.

PENA, Sérgio; BORTOLINI, Maria. (2004), “Pode a genética definir quem deve se beneficiar das cotas universitárias e demais ações afirmativas?" Estudos Avançados, vol. 18, n 50, pp. 31-50.

PINHEIRO, Camila. (2016), Estado, extensão rural e economia doméstica no Brasil. Dissertação (Mestrado em História). Universidade Federal do Fluminense, Niterói.

RAWLS, John. (1997), Uma teoria da justiça. São Paulo: Martins Fontes.

RIBEIRO, Ione; ARAUJO, Fernanda; TOMASI, Juliane. (2010), “Seleção meritocrática versus desigualdades sociais: quem são os inscritos e os classificados nos vestibulares da UFSC (1998-2007)?" Linhas Críticas, vol. 16, n 31, pp. 391-418.

RIBEIRO, Matilde. (2003), "Pela promoção da igualdade racial". Folha de S. Paulo, 20 de novembro, A3.

RUSCHEL, Elizete; VALLE, Ione. (2010), “Ideologia meritocrática e a reflexão acadêmica: a contribuição da Revista Perspectiva do CED/UFSC (1983-2005)". Perspectiva, vol. 28, n 2 , pp. 649-675.

SANTANA, Elaine. (2010), “As políticas públicas de ação afirmativa na educação e sua compatibilidade com o princípio da isonomia: acesso às universidades por meio de cotas para afrodescendentes". Ensaio: Avaliação e Políticas Públicas em Educação, vol. 18, $\mathrm{n}^{\circ} 69$, pp. 737-759.

SANTOS, Sales et al. (2008), “Ações afirmativas: polêmicas e possibilidades sobre igualdade racial e o papel do estado". Revista Estudos Femininos, vol. 16, n³, pp. 913-929. 
Política de Cotas e Meritocracia: Uma Análise da Percepção de Professores Universitários

SILVA, Maria; PACHECO, Jairo. (2013), "As cotas na Universidade Estadual de Londrina: balanço e perspectivas". In: J. Santos (org.), O impacto das cotas nas universidades brasileiras (2004-2012). Salvador: CEAO.

SOUZA, Andreliza; BRANDALISE, Mary. (2011), "Política de cotas e democratização do acesso ao ensino superior". In: Anais do XI Colóquio Internacional sobre Gestão Universitária na América do Sul. Florianópolis, 14-16 de dezembro.

UFV (Universidade Federal de Viçosa). (2018), UFV em Números. Disponível em: http:/ / www.ppo.ufv.br/wp-content/uploads/2018/11/UFV-EM-N\%C3\%9AMEROS-2018Gr\%C3\%A1fica.pdf. Acesso em 8 de junho de 2020.

VELLOSO, Jacques. (2009), “Cotistas e não-cotistas: rendimento de alunos da Universidade de Brasília". Cadernos de Pesquisa, vol. 39, n 137, pp. 621-644.

VIEIRA, Cecilia et al. (2013), "Reflexões sobre a meritocracia na educação brasileira". Revista Reflexão e Ação, vol. 21, pp. 316-334.

WALZER, Michael. (2003), Esferas da justiça. Uma defesa do pluralismo e da igualdade. São Paulo: Martins Fontes.

YOUNG, Michael. (1958), The rise of meritocracy. Harmondworth: Penguin. 


\section{RESUMO}

\section{Política de Cotas e Meritocracia: Uma Análise da Percepção de Professores Universitários}

As cotas completam 16 anos a partir das experiências nas universidades estaduais. Contudo, desde o seu início, intensos debates são registrados, cuja discussão perpassa os ideais de mérito e de igualdade de condições. Nesse contexto, o artigo tem por objetivo compreender sob a ótica do discurso de professores universitários como a justiça é manifesta nas ações afirmativas. Em termos metodológicos, recorreu-se a uma pesquisa qualitativa através de entrevistas com 26 docentes de uma instituição pública. Os resultados apontam que a maioria se aproxima de um discurso da meritocracia, todavia, sem negar a relevância das cotas. Observou-se também que, mesmo diante de dados já suficientes para a análise, os discursos se fundam em predições, sem, contudo, ilustrar experiências para a corroboração argumentativa. Em conclusão, coloca-se em evidência a importância da publicização de informações que qualifiquem o debate, já que se prevê para os próximos anos a revisão da ação afirmativa.

Palavras-chave: ação afirmativa; justiça; ensino superior; Lei de Cotas; docentes

\section{ABSTRACT \\ Quota and Meritocracy Policy: An Analysis of the Perception of University Teachers}

The quotas complete 16 years of experience in state universities. However, since its beginning, intense debates have been registered, whose discussion runs through the ideals of merit and equal conditions. In this context, the article aims to understand from the perspective of university professors' discourse how justice is manifested in affirmative actions. In methodological terms, qualitative research was conducted through interviews with 26 professors from a public institution. The results show that the majority approaches a discourse of meritocracy, however, without denying the relevance of quotas. It was also observed that, even with data already sufficient for analysis, the speeches are based on predictions, without, however, illustrating experiences for argumentative corroboration. In conclusion, the importance of publicizing information that qualifies the debate is highlighted, as the affirmative action review is expected to take place in the coming years.

Keywords: affirmative action; justice; higher education; Quota Law; teachers 


\section{RÉSUMÉ}

Politique de Quota et de Méritocratie: Une Analyse de la Perception des Enseignants Universitaires

Les quotas complètent 16 années d'expérience dans les universités d'État. Cependant, depuis ses débuts, des débats intenses ont été enregistrés, dont la discussion passe par les idéaux du mérite et des conditions d'égalité. Dans ce contexte, l'article vise à comprendre du point de vue du discours des professeurs d'université comment la justice se manifeste dans les actions positives. Sur le plan méthodologique, une recherche qualitative a été menée à travers des entretiens avec 26 professeurs d'un établissement public. Les résultats montrent cependant que la majorité aborde un discours de méritocratie, sans nier la pertinence des quotas. Il a également été observé que, même avec des données déjà suffisantes pour l'analyse, les discours sont basés sur des prédictions, sans toutefois illustrer les expériences de corroboration argumentative. En conclusion, l'importance de publier les informations qui qualifient le débat est soulignée, car l'examen de la discrimination positive devrait avoir lieu dans les années à venir.

Mots-clés: action positive; justice; enseignement supérieur; loi sur les quotas; enseignants

\section{RESUMEN}

Politica de Cuotas y Meritocracia: Un Análisis de la Percepción de Profesores Universitarios

Las cuotas completan 16 años de experiencia en universidades estatales. Sin embargo, desde sus comienzos, se han registrado intensos debates, cuya discusión recorre los ideales de mérito e igualdad de condiciones. En este contexto, el artículo pretende comprender desde la perspectiva del discurso de los profesores universitarios cómo se manifiesta la justicia en las acciones afirmativas. En términos metodológicos, la investigación cualitativa se realizó a través de entrevistas con 26 profesores de una institución pública. Los resultados muestran que la mayoría se acerca a un discurso de meritocracia, sin negar la relevancia de las cuotas. También se observó que, incluso con datos ya suficientes para el análisis, los discursos se basan en predicciones, sin embargo, sin ilustrar las experiencias de corroboración argumentativa. En conclusión, se destaca la importancia de publicitar la información que califica el debate, ya que se espera que la revisión de acción afirmativa tenga lugar en los próximos años.

Palabras clave: acción afirmativa; justicia; educación superior; ley de cuotas; docentes 